\title{
Methodology for determination of heat losses from infiltration and ventilation and heat gains from people in overall energy balance of the building
}

\author{
Dana Brazhanova ${ }^{1 *}$, Vyacheslav Stoyak ${ }^{1}$, Madina Ibragimova $^{1}$, and Angel Terziev ${ }^{2}$ \\ ${ }^{1}$ Non-commercial “Almaty University of Power Engineering and Communication" JSC, Almaty, \\ Republic of Kazakhstan \\ ${ }^{2}$ Deptartment of "Power Engineering and Power Machines", 8 Kliment Ohridski blvd., Technical \\ University of Sofia, 1000 Sofia, Bulgaria
}

\begin{abstract}
This paper proposes a new methodology of determining the building heat losses associated with natural and (or) forced air ventilation, based on continuous measurements of the temperature, humidity and carbon dioxide concentration in the air. Determining the flow rate of infiltrating air is performed by the active and passive experimental methods. The proposed method allows determining the exact amount of heat losses associated with ventilation or infiltration of the building under environmental conditions. In addition, the paper proposes an algorithm of calculating the actual number of people present in the room and the associated heat gains based on the air composition analysis. The proposed methods can be used as tools for conducting energy inspections of buildings and structures, as well as be part of effective building energy supply management systems.
\end{abstract}

\section{Introduction}

The following four factors influence the heat sensations and the thermophysical state of a person: temperature, air humidity, air distribution and the temperature of the enclosing surfaces of the room; at the same time, the air mobility is one of the most important factors.

The human factor, in turn, also affects the airflow mobility, changes its direction and speed. Also, a person is a source of air pollution, as it produces heat and moisture [1]. At the same time, building ventilation is the area where it is necessary to find the optimal solution between the energy efficiency and the indoor air quality.

In buildings equipped with natural and/or forced ventilation, the movement of a person in a building is one of the key factors for the resulting air exchange rate, which affects the indoor air quality and thermal comfort. The absence of the air movement in the room or its excessively low values are associated with poor ventilation. The reason for unpleasantness

\footnotetext{
* Corresponding author: dana b.k@,bk.ru
} 
in a poorly ventilated room is explained by the fact that in the absence of the air movement around the human body, a thin motionless air layer is shaped that quickly becomes saturated with water vapor, which further takes its temperature and reduces heat transfer [2]. Because of this, it is necessary to maintain a certain air velocity in order to maintain comfortable room conditions.

A number of works $[3,4]$, are dealing with calculation of energy costs needed for air ventilation in the room. When designing buildings and structures, the regulatory documents [5-7] should be considered. The standard method of calculating specific characteristics of a building, $K_{\text {vent }}, \mathrm{W} /\left(\mathrm{m}^{3} \cdot \mathrm{K}\right)$ in the considered works and normative documents are identical and are reduced to calculation by Eq. 1:

$$
K_{\text {vent }}=0.28 \cdot n_{B} \cdot \beta_{B} \cdot \rho_{B} \cdot c \cdot\left(1-\kappa_{e f}\right)
$$

where $\quad c$ is specific heat capacity of the air that is equal to $1 \mathrm{~kJ} /(\mathrm{kg} \cdot \mathrm{K})$;

$\beta_{B}$ is the coefficient of the air volume reducing in the building;

$\rho_{B}$ is the average density of the inlet air within the heating period, $\mathrm{kg} / \mathrm{m}^{3}$;

$\kappa_{e f}$ is the heat exchanger efficiency;

$n_{B}$ is the average air exchange of the building, $\mathrm{h}^{-1}$.

In the above presented standards calculating heat losses with ventilation and infiltration of building envelop, the authors accept the calculated values of the outdoor and indoor air temperatures, normalized values of the supply air as the input data. The values of density and heat capacity of the air are assumed to be constant, which indicates the absence of taking into account the dynamics of the ventilation effect on the thermal balance of the building as a whole. In addition, humidity is not taken into account in the heat loss calculations [8].

In the work of V. Zhitov [9] presented methodology of studying air exchange in the premises of residential buildings by means of carrying out a full-scale experiment. The experiment consisted of mounting STS-5 radiation detectors in certain places of the room, then supplying inactive $\mathrm{CO}_{2}$ gas from the cylinder to the center of the object under study, and the $\mathrm{Kr}-85$ radioactive gas was introduced into this gas flow through the tee from the container balloon. The volume of the supplied air is controlled by a thermoregulatory flow meter that provides supplying of the specified $\mathrm{Kr}-85$ to the room [9]. The trace gas mixture was mixed in the test volume with a regular fan with horizontally oriented blades. Then, after 10-15 minutes of mixing and the same interval of the standing time, there began counting the number of pulsations. The air exchange rate was determined as a function of the slope of the incidence straight of the indicator averaged concentration with the abscissa axis.

\section{Problem description}

The method presented in this work is difficult to implement, because it requires the presence of the inaccessible radioactive gas $\mathrm{Kg}-85$ and the entire set of measuring instruments, regulators, signal amplifiers.

Today, the most accurate way to determine heat losses with air ventilation and infiltration is the method using the Aero Door, a set for determining air permeability of the building enclosing structures.

The method is based on developing differential pressure (pressure inside the house and outdoor pressure) with a special set, an Aero Door [10]. Figure 1 shows the principle of operation of this experimental equipment. 


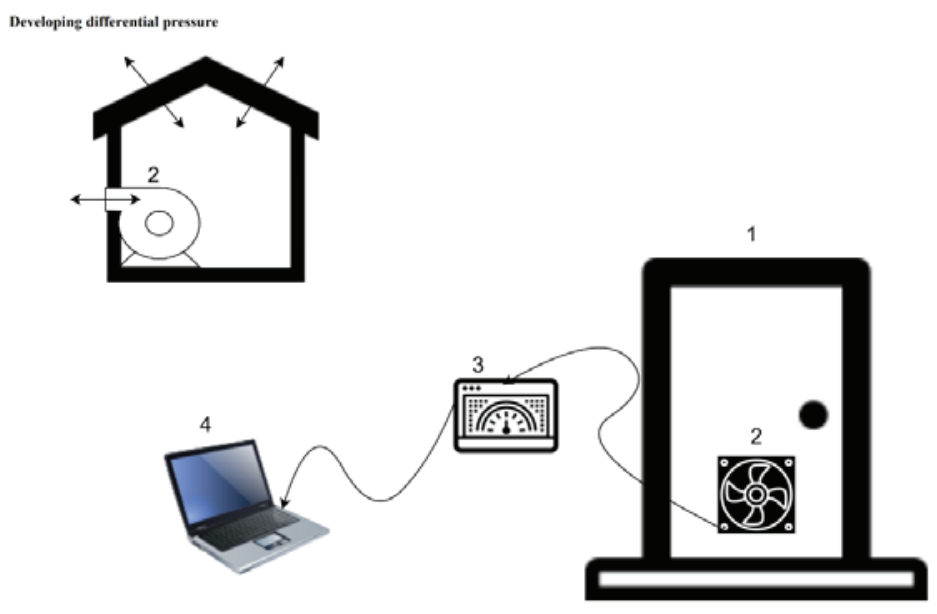

1 - Aero Door, 2 - fan, 3 - anemometer, 4 - personal computer

Fig. 1. Structural diagram of the Aero Door operation

For carrying out studies, an Aero Door set is mounted in the window of the building under examination or in the opening of the external door. The internal doors of the building remain open, the windows close, the ventilation system is turned off and sealed. The fan is used to develop excess pressure or vacuum in the test object, while measuring the airflow through the fan. The measurement results give a characteristic of the air permeability of the building, namely the parameter of the frequency of air exchange, the information of the presence and the size of leak tight integrity damage.

Similar studies at the Aero Door sets have been carried out by many authors in recent years [1]. This method is the most popular in the field of leak tight integrity measurement.

In recent years, acoustic methods have appeared. They are trying to quantify the air flow based on ultrasonic contraction recorded between the wave transmitter on one side of the enclosing surface and the wave receiver on the other side. Further development of these methods would be useful in searching for an effective method for measuring air leakage. In addition to the effectiveness of these methods in localizing leakage, they are sufficiently tested for the quantitative assessment of air leakage [11].

When using the Aero- Door method, it is important to consider one of the main parameters: the material of the building walls. There are various types: frames, logs, blocks made of autoclaved aerated concrete, lightweight aggregate, brick, concrete blocks and concrete elements. The results presented in [12] show that wet mechanically plastered masonry seems more airtight than dry masonry and steel structures. In paper [13], there are examined combined materials and their breathability.

The term "airtightness" refers to the intensity of an uncontrolled air flow through a building structure as a result of the pressure difference between indoor and outdoor air. Uncontrolled air leakage can occur through connections between different materials, dilatations and other permeable points in the building structure. Before starting the measurement of air tightness in buildings, it is necessary to collect the data of the floor area, volume and surface area of the building structure [14]. This data can be divided into main groups:

- general information of the building;

- information of the building structure (dimensions and types of joinery, types of window glazing, layers and layer thickness of walls, ceilings and roofs);

- meteorological data (the temperature, wind speed, air pressure, relative humidity and precipitation). 
In addition to determining air permeability of the building enclosing structures, it is also possible to identify places of latent defects in building structures, which is carried out using a comprehensive examination using a thermal imager and an Aero Door. Standard measurements with a thermal imager are limited in their information content and allowable time. They demonstrate no more than $10-20 \%$ of the real volume of existing defects [8]. The use of Aero Doors removes a significant drawback of using a thermal imager: seasonality of surveys, allowing thermal imaging surveys in summer.

Despite the obvious advantages of the existing modern technology for conducting air permeability studies of building envelopes based on an Aero Door and a thermal imager, this system has a number of significant disadvantages and limitations:

- due to the significant differences between the natural conditions of the building and the conditions of testing, the results of such measurements cannot be interpreted as direct measurements of the air exchange rate of the building in natural conditions. Accordingly, the calculated values of heat losses with ventilation and infiltration based on the obtained data obviously exceed the actual values;

- the concept of testing is accepted such that all sides of the building enclosing structures are experiencing the same pressure. However, in reality, a foundation slab or floor will almost never receive such pressure. Thus, the test results do not provide information of the tightness of the floor compared to the ceiling;

- the heated air in the building is less dense than the supply cold air from the environment, so houses that have been tested in cold weather seem to be more "airtight" than they really are (about 1 percent for each $6{ }^{\circ} \mathrm{C}$ difference between the temperature indoor and outdoor) [15]. Otherwise, the research results will indicate the amount of less dense air passing through the fan door, and not the amount of colder, denser air passing through the holes and crevices of the building.

\section{Experimental study. Results}

In this paper, a method of calculating heat losses associated with natural and/or forced ventilation/infiltration of a building based on continuous measurements of the temperature, humidity and carbon dioxide concentration in the air is proposed. The method consists in the experimental determination of the airflow in the studied object due to the indicator of the carbon dioxide concentration reduction. At the same time, the humidity and air temperature indoors and outdoors are taken into account, i.e. the integral problem of heat and mass transfer is considered [8].

Determining the airflow infiltrating through leaks of envelopes and/or leaving with ventilation, the proposed method is carried out in two ways: an active and passive experiment.

The active method of carrying out experiment consists in the following (Figure 2):

1) mounting special sensor units with sensors for the temperature, humidity and $\mathrm{CO}_{2}$ concentration inside the studied object and outside, to measure environmental parameters;

2) specially developed software for receiving, processing and archiving collected measurement information;

3) supplying inactive $\mathrm{CO}_{2}$ gas from the cylinder to the center of the room.

According to the diagram of the active experiment, presented in accordance with Figure $2, \mathrm{CO}_{2}$ gas is supplied from the cylinder to the center of the room until the information of the maximum concentration of carbon dioxide in the room is displayed on the program interface. After that, the room is closed and the system independently performs continuous measurements of the temperature, relative humidity, $\mathrm{CO}_{2}$ concentration in the indoor and outdoor air with saving data to a file within 6-10 hours [8]. 


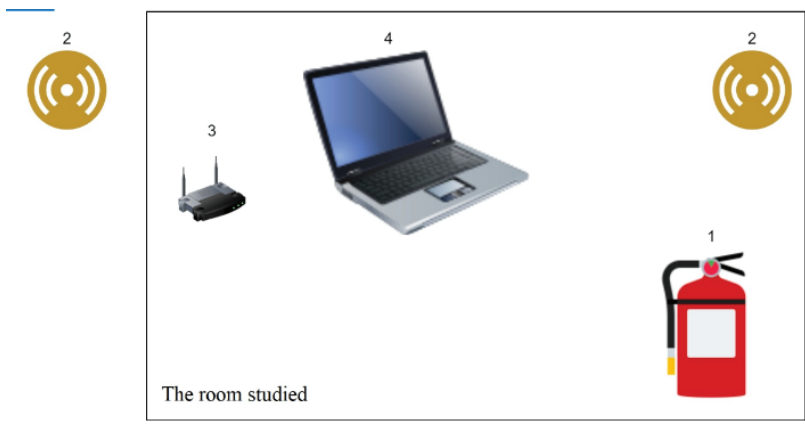

1 - cylinder with $\mathrm{CO}_{2}, 2$ - sensor unit, 3 - wireless network receiver, 4 - personal computer with the installed software

Fig. 2. Diagram of carrying out an active experiment

Figure 3 shows the results of measurements of the $\mathrm{CO}_{2}$ concentration in the indoor and outdoor air.

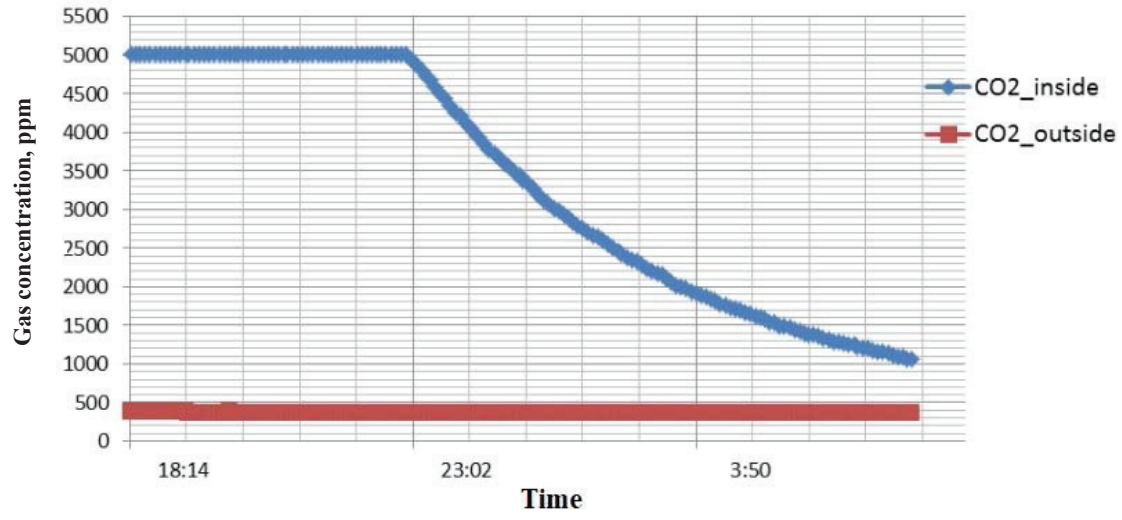

Fig. 3. $\mathrm{CO}_{2}$ concentration change in the room (active experiment)

The procedure of carrying out a passive experiment is identical to the procedure for an active experiment, except that in this case, the source of carbon dioxide is the natural discharge of the inhabitants of the studied object [8].

The results of measurements in a passive experiment are presented in Figure 4.

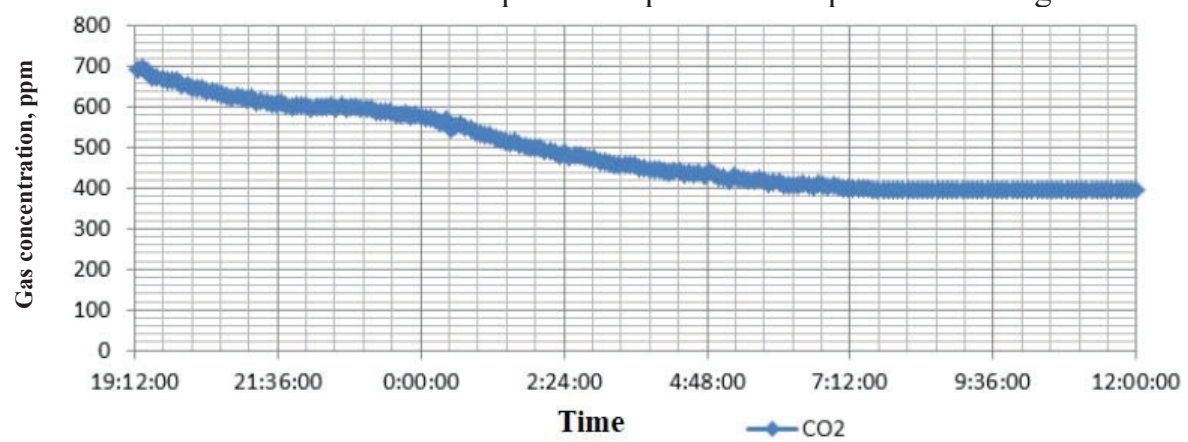

Fig. 4. $\mathrm{CO}_{2}$ concentration change in the room (passive experiment)

The calculation of the infiltrating airflow rate $\mathrm{G}, \mathrm{kg} / \mathrm{s}$, according to the results of measurements, complies with Eq. 2: 


$$
G=\frac{\Delta C_{2} \cdot V \cdot \rho}{\Delta \tau \cdot\left(C_{2}-C_{1}\right)}
$$

where

$\Delta C_{2}$ is the $\mathrm{CO}_{2}$ concentration at the selected point, ppm;

$C_{1}, C_{2}$ are respectively the previous and the next values of the $\mathrm{CO}^{2}$ concentration relative to the selected point $\Delta C_{2}$, ppm;

$\Delta \tau$ is the process duration, $\mathrm{s}$;

$\rho$ is the air density, $\mathrm{kg} / \mathrm{m}^{3}$;

$V$ is the volume of the studied room, $\mathrm{m}^{3}$.

The calculation of the indoor and outdoor air enthalpy based on the measured values of the temperature and relative humidity is carried out according to the following formulas.

The pressure of saturated water vapor over a flat surface of water $(t>0)$ or ice $(t \leq 0), \mathrm{kPa}$ is determined by Eq. 3:

$$
P_{H}=0,6112 \cdot \exp \left[\frac{\alpha \cdot t}{\beta+t}\right]
$$

where $\quad \alpha_{B}, \beta_{B}$ are constants for water, $\alpha_{B}=17.504, \beta_{B}=241.2$;

$t$ is the temperature, $\mathrm{K}$.

The relative humidity $\varphi, \%$ is determined by Eq. 4 :

$$
\phi=\frac{P_{\Pi}}{P_{\mathrm{H}}} \cdot 100 \%
$$

where $\quad P_{\Pi}$ is the partial pressure of water vapor, $\mathrm{kPa}$.

Water content $\mathrm{d}, \mathrm{g} / \mathrm{kg}$ is determined by formula 5 :

$$
d=621,98 \cdot \frac{P_{\Pi}}{P_{b}-P_{\Pi}}
$$

where $\mathrm{P}_{\mathrm{b}}$ is the barometric pressure, $\mathrm{kPa}$ (is accepted equal to $101,325 \mathrm{kPa}$ ).

Specific enthalpy of the wet air h, $\mathrm{kJ} / \mathrm{kg}$ is determined by Eq. 6 :

$$
h=1.006 \cdot t+\frac{d}{1000} \cdot(2501+1.805 \cdot t)
$$

Thus, the amount of heat losses with infiltration and ventilation $\mathrm{W} / \mathrm{m}^{3}$ is calculated by Eq. 7:

$$
Q_{\text {vent }}=1000 . G\left(h_{\text {out }}-h_{\text {in }}\right)
$$

where $\quad h_{\text {out }}, h_{\text {in }}$ are respectively enthalpy of the outdoor and indoor air. 
The proposed method of calculating heat losses associated with natural and/forced ventilation/infiltration of a building based on continuous measurements of the temperature, humidity and carbon dioxide concentration in the air, allows:

- determining the exact amount of heat losses associated with ventilation/infiltration of the building;

- calculating heat losses under natural conditions of operation of the studied object, which does not allow using the Aero Door method discussed above;

- it is a worthy substitute for the most popular and expensive method of determining the air permeability of building envelopes based on the use of the Aero Door method discussed above.

It is known that inhabitants of residential and public buildings play a large role not only as consumers of energy but also as sources of thermal energy.

There are a large number of works that deal with studying the impact of life and people's living standards on energy demand, and their role in the overall energy balance of buildings [16-18].

The released heat from people depends on the intensity of the work performed and the parameters of the surrounding air. The heat generated by people consists of tangible (explicit), i.e. transmitted into the air of the room by convection and radiation, and latent heat spent for the evaporation of moisture from the skin surface and from the lungs.

The amount of the heat released from people is determined by Eq. 8, expressed in Watts:

$$
Q_{\text {people }}=n \cdot q . k
$$

where $\mathrm{n}$ is the number of people;

$\mathrm{q}$ is heat release by one adult, $\mathrm{W} / \mathrm{prs}$.

$k$ ( $k=1$ for man ; $k=0,85$ for women ; $k=0,75$ for children)

The $\mathrm{q}$ indicator depends on the temperature, humidity, and the degree of physical activity of a person. In various sources there are given different figures. So, according to [19] for calculation of heat from people in public and administrative buildings, it is recommended to take the heat value per person equal to $90 \mathrm{~W} /$ person.

The main problem in calculating the heat input from people is exact determining their number at the studied object during the period of energy studies.

Improving residential energy consumption is an essential element of any government portfolio of energy efficiency policies and climate change mitigation programs.

According to the strategic plan of the International Energy Agency (IEA) for the period from 2008 to 2018, energy efficiency programs were introduced as the key part of energy policy decisions, as they can provide the fastest and most cost-effective way to solve energy security, environmental and economic problems. [20].

So, the most flexible and popular software packages designed for energy simulation of buildings and structures, such as Energy Plus, TRNSYS, CHVAC and others, use the schedule of visits to certain rooms of the building when calculating heat input from people. This method does not allow determining the exact number of people in the current time of, in connection with the dynamic life of office, public and residential buildings [8].

The paper proposes a new method of indirect measurements of heat input from people in the room. The method consists in determining the current value of the number of people in the room, due to the measured rate of growth of $\mathrm{CO}_{2}$ concentration in the room.

Before carrying out measurements and calculations, the system determines the basic indicator of the level of the $\mathrm{CO}_{2}$ concentration in the room in the absence of people. Then, at certain intervals, the measured values of the $\mathrm{CO}_{2}$ concentration are compared with the base, 
and when detecting an increase in the concentration of carbon dioxide, the number of people is calculated.

It is known that a person emits about 20 liters of carbon dioxide on average per hour [21]. Knowing this, we can determine the amount of $\mathrm{CO}_{2}$ exhaled by a person in the volume of the room $\mathrm{L}_{\mathrm{CO}_{2}}, \mathrm{ml} / \mathrm{m}^{3}$ by Eq. 9:

$$
L_{\mathrm{CO}_{2}}=\frac{G\left(\mathrm{CO}_{2}\right)}{V_{\text {room }}}
$$

where $\quad \mathrm{G}\left(\mathrm{CO}_{2}\right)$ is the average standard value of the $\mathrm{CO}_{2}$ concentration, ml;

$V_{\text {room }}$ is the room volume, $\mathrm{m}^{3}$.

Then the number of people is calculated by formula 10 :

$$
L_{\text {people }}=\frac{\mathrm{CC}_{\mathrm{CO}_{2}}-\mathrm{CB}_{\mathrm{CO}_{2}}}{L_{\mathrm{CO}_{2}}}
$$

where $\quad \mathrm{CC}_{\mathrm{CO}_{2}}$ is the current value of the $\mathrm{CO}_{2}$ concentration growth $\left(1 \mathrm{ppm}=1 \mathrm{ml} / \mathrm{m}^{3}\right)$;

$\mathrm{CB}_{\mathrm{CO}_{2}}$ is the basic value of the $\mathrm{CO}_{2}$ concentration in the room in the absence of people, $\mathrm{ppm}\left(1 \mathrm{ppm}=1 \mathrm{ml} / \mathrm{m}^{3}\right)$.

Then, by formula 9 is calculated the current value of the amount of heat released from people.

The proposed method of indirect measurements of heat input from people in the room will allow:

- calculating the instantaneous value of heat input from people;

- the most accurate determining, in comparison with the existing methods, the number of people in the room by taking into account the growth rate of the $\mathrm{CO}_{2}$ concentration;

- taking into account such an important but difficult to determine indicator, as the degree of physical activity of a person, due to taking into account the concentration of $\mathrm{CO}_{2}$ emitted, which growth of the indication directly depends on the intensity of the work performed by a person.

Intelligent residential buildings based on energy efficiency programs significantly reduce energy consumption and $\mathrm{CO}_{2}$ emissions. Moreover, since these buildings can appropriately manage energy consumption, they can participate in high-level demand response programs.

\section{Conclusion}

In the course of the work, the following results were obtained:

1. A new method of determining heat losses of buildings associated with natural and/or forced ventilation based on continuous measurements of the temperature, humidity and concentration of carbon dioxide in the air. This method is an alternative to the expensive method of assessing air permeability of building envelopes using the Aero Door.

2. A new method of indirect measurements of actual heat input from people in the room. The method consists in determining the current value of the number of people in the room, due to the measured rate of the $\mathrm{CO}_{2}$ concentration growth in the room. 
The proposed methods can be used as tools for conducting energy inspections of buildings and structures, and be an integral part in the design of efficient building energy supply management systems.

\section{References}

1. M. Prignon, G. Van Moeseke, Factors influencing airtightness and airtightness predictive models: A literature review, Energy and Buildings, 146 (2017), p.p. 87-97.

2. M. Igor, A. S. Anđelković, V. Munćan, M. Kljajić, D. Ružić. Influence of indoor environmental quality on human health and productivity, Journal of Cleaner Production, 217, April 20, (2019), p.p. 646-657.

3. V. I. Livchak, Methodology of calculating the specific annual consumption of thermal energy for heating and ventilation of buildings, ABOK (2010)

4. $\mathrm{Yu}$ Ya Kuvshinov, Calculation of annual energy consumption by ventilation and air conditioning systems, ABOK, (2006)

5. Code of rules of the Republic of Kazakhstan 4.02-101-2012 «Heating, ventilation and air conditioning»》

6. Building standards of the Republic of Kazakhstan 4.02-01-2011 «Heating, ventilation and air conditioning»

7. Code of rules of the Republic of Kazakhstan 2.04-01-2017 «Building climatology»

8. M. V. Ibragimova, Developing hardware software methodological complex for automated energy audit of buildings based on wireless sensor systems, The dissertation for the degree of Doctor of Philosophy (PhD), (2018), p. 145

9. V. G. Zhitov, Research and providing parameters of the microclimate and public buildings by methods of optimal design of the experiment, The dissertation for the degree of candidate of technical sciences (2007), $183 \mathrm{p}$.

10. V. N. Panteleyev, The results of the test of enclosing structures for breathability by technology Blower Door - Aero Door, Test report dated June 14, (2013)

11. G. Raman, K. Chelliah, M. Prakash, R.T. Muehleisen, Detection and quantification of building air infiltration using remote acoustic methods, in: 43rd International Congress on Noise Control Engineering, (2014), pp. 16-19.

12. D. Johnston, D. Miles-Shenton, M. Bell, J. Wingfield, Airtightness of buildings towards higher performances, Tech. rep., Leeds Beckett University, Final Report, 2011.

13. W. Pan, Relationships between air-tightness and its influencing factors of post-2006 new-build dwellings in the $\{\mathrm{UK}\}$, Build. Environ. 45, (2010), p.p. 2387-2399.

14. H. Krstic', Z. Koski, I. Otkovic, M. Spanic. Application of neural networks in predicting airtightness of residential units. Energy and Buildings, 84 (2014), p.p. 160-168

15. D. Keefe, Diagnose problems in the building envelope with blower door, The journal of light construction, (2010).

16. V. Fabi, V. Barthelmes, M. Schweiker, S. Corgnati, Insights into the effects of occupant behaviour lifestyles and building automation on building energy use, Energy Procedia, 140, (2017), p.p. 48-56

17. N. Nord, T. Tereshchenko, L. H. Qvistgaard, I. S. Tryggestad, Influence of occupant behavior and operation on performance of a residential Zero Emission Building in Norway, Energy and Buildings, (2018), p.p. 75-88 
18. J. Zhan, W. Liu, F. Wu, Z. Li, C. Wang, Life cycle energy consumption and greenhouse gas emissions of urban residential buildings in Guangzhou city, Journal of cleaner production, (2018).

19. Code of rules of the Republic of Kazakhstan 2.04-04-2011 «Thermal protection of buildings»

20. M. Oskouei, B. Mohammadi-Ivatloo, M. Abapour, A. Ahmadian, Md. Jalil Piran, A novel economic structure to improve the energy label in smart residential buildings under energy efficiency programs, Journal of Cleaner Production, 260 (2020)

21. I. M. Kvashnin, I. I. Gurin, Towards standardizing air exchange for the $\mathrm{CO}_{2}$ concentration in the indoor and outdoor air, ABOK, 4, (2008).

22. CSTC, L'étanchéité á l'air des batiments, technical information note, (2015).

23. P. F. Pereira, N. M. Ramos, R. M. S. F. Almeida, M. Lurdes, E. Barreira, Occupant influence on residential ventilation patterns in mild climate conditions, 11th Nordic Symposium on Building Physics, NSB2017, (2017)

24. S. Moeller, I. Weber, F. Schroder, A. Bauer, H. Harter, Apartment related energy performance gap - how to address internal heat transfers in multi-apartment buildings, Journal of Energy \& Buildings, 16, (2020). 